\title{
ASOSIASI KELIMPAHAN KEPITING BAKAU DENGAN KEBERADAAN JENIS VEGETASI MANGROVE KELURAHAN SUMBER JAYA KECAMATAN KAMPUNG MELAYU KOTA BENGKULU
}

\author{
Oleh \\ Bayu Syahrera1, Dewi Purnama ${ }^{2}$, Zamdial Ta'alidin ${ }^{3}$ \\ ${ }^{\left(1^{*}\right)}$ Jurusan IImu Kelautan Fakultas Pertanian Universitas Bengkulu, Bengkulu \\ $\left.{ }^{2 *}{ }^{*}\right)$ Dosen IImu Kelautan Universitas Bengkulu( \\ Email : bayusyahrera@ymail.com \\ Received July 2016, Accepted August 2016
}

\begin{abstract}
ABSTRAK
Penelitian ini dilakukan di Kelurahan Sumber Jaya, Kecamatan Kampung Melayu Kota Bengkulu, yang bertujuan untuk mengetahui kelimpahan kepiting bakau, menganalisis hubungan asosiasi kelimpahan kepiting bakau dengan jenis vegetasi mangrove tingkat pohon, menghitung dan menganalisis indeks keanekaragaman, keseragaman, dominasi kepiting bakau, dan parameter fisika kimia perairan. Metode yang digunakan adalah metode survei. Pengambilan sampel dan pengukuran fisika kimia perairan dilakukan secara in-situ di ekosistem hutan mangrove Kelurahan Sumber Jaya. Hasil pengamatan ditemukan 2 spesies kepiting bakau dengan kelimpahan tertinggi terdapat pada stasiun 1 (satu) sebanyak 157 ind/ha diikuti stasiun 3 (tiga) sebanyak 100 ind/ha dan stasiun 2 (dua) sebanyak 61,67 ind/ha. Kelimpahan tertinggi pada stasiun 1 (satu) dan 3 (tiga) yaitu jenis Scylla paramamosain, sedangkan pada stasiun 2 (dua) adalah jenis Scylla olivacea. Indeks keanekaragaman berkisar antara 0,562-0,976, indeks keseragaman berkisar antara 0,562-0,976, dan indeks dominasi berkisar antara 0,5160,771 , secara keseluruhan dalam keadaan tidak stabil, jumlah spesies tidak merata dan terdapat kecenderungan spesies. Kepiting bakau jenis Scylla paramamosain berasosiasi dengan vegetasi mangrove jenis Sonneratia alba dengan nilai korelasi 0,52 , sedangkan jenis Scylla olivacea berasosiasi dengan vegetasi mangrove jenis Rhizophora apiculata dengan nilai korelasi 0,23 . Hasil pengukuran Parameter fisika kimia perairan didapatkan suhu rata-rata $27,35{ }^{\circ} \mathrm{C}$, salinitas rata-rata $25,29 \%$, derajat keasaman $(\mathrm{pH})$ rata-rata 7,26 $\%$. Kondisi ini menujukan bahwa perairan hutan mangrove tersebut masih mendukung kepiting bakau dan hutan mangrove itu sendiri.
\end{abstract}

Kata kunci : kepiting bakau, mangrove, kelimpahan, sumber jaya.

\section{ABSTRACT}

The research was conducted in Kelurahan Sumber Jaya, Kecamatan Kampung Melayu Kota Bengkulu. It aims to know the abundance of mangrove crab, to analyzes the relationship between mangrove crab and the kinds of mangrove vegetation tree level, to calculates and to analyzes the diversity index, uniformity, dominance of mangrove crabs and physics chemistry water parameters. The method used was survey method. The sampling and measurement of physics chemistry water were conducted by in-situ in the mangrove forest ecosystem of Kelurahan Sumber Jaya. Based on the observation, it was found that there are two species of mangrove crab with the highest abundance at the station 1 (one) as many as $157 \mathrm{ind} / \mathrm{ha}$, the next is station 3 (three) as many as $100 \mathrm{ind} / \mathrm{ha}$ and then station 2 (two) as many as 61,67 ind/ha. The highest abundance in the station 1 and station 3 are types of Scylla paramamosain, while in the station 2 is types of Scylla olivacea. Diversity index ranged between 0562 to 0976 and dominance index ranged from 0.516 to 0771 , the overall status is an unstable, the number of species is uneven and there is a tendency of species. Mangrove crab, type of Scylla paramamosain associated with mangrove vegetations, Sonneratia alba with the correlation value is 0.52 , while the type of Scylla olivacea associated with mangrove vegetation types, Rhizophora apiculata 
with the correlation value is 0,23 . The measurement result of phycis chemistry water obtained average temperature of $27.35^{\circ} \mathrm{C}$, average salinity $25.29 \%$, the degree of acidity $(\mathrm{pH})$ average of $7.26 \%$. This condition indicates that the waters of the mangrove forests still support the mangrove crab and the mangrove forest it self.

Keywords : mangrove crab, mangrove, abudance, sumber jaya.

\section{PENDAHULUAN}

Kepiting bakau (Scylla serrata) adalah jenis kepiting yang hidup di habitat mangrove hutan bakau. Scylla serrata merupakan komoditas ekspor disamping rajungan (Portunus pelagicus). Bila rajungan mempunyai nilai ekonomis penting sebagai daging dalam kaleng atau dalam keadaan beku, maka kepiting bakau dapat dipasarkan dalam keadaan hidup karena lebih tahan hidup di luar air (Juwana, 2004 dalam Wijaya, 2011).

Kepiting bakau merupakan komoditas bernilai ekonomi tinggi serta berasosiasi langsung dengan ekosistem hutan mangrove sehingga hewan ini sangat erat kaitanya serta begitu bergantung pada kondisi kawasan hutan mangrove sebagai habitat asalnya, sehubungan dengan peranan hutan mangrove selain sebagai penahan gelombang juga sebagai tempat bernaung dan mencari makan kepiting bakau .

Melihat pentingnya kepiting bakau dari segi bioekologi dan ekonomi yang secara khas berasosiasi dengan hutan mangrove sebagai habitatnya di sekitar kawasan Kelurahan Sumber Jaya Kecamatan Kampung Melayu Kota Bengkulu, maka perlu adanya kajian tentang kelimpahan kepiting bakau yang berasosiasi dengan keberadaan jenis vegetasi mangrove tersebut untuk mengetahui informasi seberapa jauh peranan suatu jenis mangrove terhadap kepiting bakau yang berfungsi sebagai tempat tinggal, tempat berlindung dan sumber makanan agar dapat dimanfaatkan dengan baik. Oleh karena itu, peneliti tertarik melakukan penelitian tentang asosiasi kepiting bakau dengan keberadaan jenis vegetasi mangrove untuk melihat jenis kepiting bakau dan mengetahui kelimpahan kepiting bakau pada hutan mangrove di kawasan Kelurahan Sumber Jaya.

Tujuan penelitian ini adalah untuk menghitung kelimpahan kepiting bakau di ekosistem hutan mangrove Kelurahan Sumber Jaya, menganalisis hubungan asosiasi kelimpahan kepiting bakau dengan jenis vegetasi mangrove tingkat pohon, menghitung dan menganalisis indeks keanekaragaman, keseragaman, dominasi kepiting bakau, serta parameter fisika kimia perairan. Hasil dari penelitian ini diharapkan dapat bermanfaat sebagai sumber informasi mengenai kelimpahan kepiting bakau pada hutan mangrove dan dapat sebagai bahan acuan untuk penelitian selanjutnya.

\section{METODE PENELITIAN}

Penelitian ini dilakukan di Kelurahan Sumber Jaya Kecamatan Kampung Melayu Kota Bengkulu, pada bulan Oktober sampai bulan Desember 2013.

Pemilihan stasiun pengamatan dilakukan secara sengaja (purposive) dengan pertimbangan bahwa daerah tersebut adalah salah satu daerah yang dijadikan oleh masyarakat untuk tempat penangkapan kepiting bakau dan kondisi hutan mangrove.

Stasiun penelitian ditentukan berdasarkan hasil survai pra penelitian secara visual yang dilakukan pada bulan September 2013. Dalam penelitian ini ditetapkan 3 stasiun dengan melihat jenis mangrove yang paling umun atau dominan ditemukan. Pada tiap stasiun akan di tarik satu garis transek tegak lurus garis pantai dan sejajar aliran sungai. Pada tiap garis transek terdapat petak sampling kuadrat yang terdiri dari 3 plot berukuran $10 \mathrm{x}$ 10 meter.

\section{Pengumpulan Data Mangrove}

Pengambilan data mangrove dengan menggunakan metode transek kuadrat 10x10 meter untuk kelompok pohon (diameter $>10 \mathrm{~cm}$ ) (Setyobudiandi $d k k$., 2009). Terdapat 3 transek kuadrat dalam satu garis transek pada satu stasiun. 


\section{Pengumpulan Data Kepiting Bakau}

Pengambilan sampel kepiting bakau dilakukan 7 kali pengulangan pada plot di setiap transek vegetasi mangrove tingkat pohon. Penangkapan kepiting bakau menggunakan alat tangkap berupa bubu berukuran diameter $30 \mathrm{~cm}$ tinggi $25 \mathrm{~cm}$ (Gambar 6). Setiap bubu diberi umpan berupa kepala ayam yang digantungkan didalamnya. Bubu diletakkan secara acak pada masing-masing plot, dimana setiap plot diletakkan sebanyak 3 bubu. Kepiting bakau yang tertangkap identifikasi jenisnya menggunakan buku identifikasi kepiting bakau (Puslit oseanografi LIPI).

\section{Pengukuran Parameter Fisika Kimia Perairan}

Pengukuran parameter fisika kimia dilakukan secara in-situ pada tiap plot di masingmasing stasiun yang meliputi beberapa parameter antara lain suhu, salinitas, serta $\mathrm{pH}$ perairan.

\section{Analisis Data}

Identifikasi jenis kepiting bakau menggunakan buku identifikasi dari Puslit Oseanografi LIPI, sedangkan untuk identifikasi mangrove menggunakan Panduan Pengenalan Mangrove oleh Noor dkk. (2006).

Kelimpahan kepiting bakau (Brower et al., 1990)

Keterangan :

$$
K=\frac{\sum n i}{A}=D i \times A
$$

$\mathrm{K}=$ Kelimpahan Jenis

$\sum \boldsymbol{n i}=$ Jumlah Individu suatu jenis

$\mathrm{A}=$ Luas Area

Kelimpahan relatif kepiting bakau (Krebs, 1972) dalam Setyobudiandi (2009)

Keterangan :

$$
K r=\frac{n i}{N} \times 100 \%
$$

$\mathrm{KR}=$ Kelimpahan relatif

$\mathrm{ni}=$ Jumlah individu spesies ke-i

$\mathrm{N}=$ Jumlah total individu semua spesies

Indeks keanekaragaman Shannon-Wiener (Brower et al., 1990)

Keterangan :

$$
H^{\prime}=-\sum_{i=1}^{n}\left(\frac{n i}{N}\right) \log 2\left(\frac{n i}{N}\right)
$$

$\mathrm{H}^{\prime}=$ Indeks keanekaragaman Shannon-Wiener

$\mathrm{Ni}=$ Jumlah individu spesies ke-i (ni)

$\mathrm{N}$ = Jumlah individu semua spesies.

Tabel 1. Nilai Indeks Keanekaragaman Shannon Wiener

\begin{tabular}{cl}
\multicolumn{1}{c}{$\begin{array}{c}\text { Nilai Tolok } \\
\text { Ukur }\end{array}$} & \multicolumn{1}{c}{ Keterangan } \\
& $\begin{array}{l}\text { Keragaman rendah, miskin, } \\
\text { produktivitas sangat rendah } \\
\text { sebagai indikasi adanya } \\
\text { tekanan yang berat dan } \\
\text { ekosistem tidak stabil }\end{array}$ \\
& \\
\hline
\end{tabular}




\section{Keragaman sedang, \\ $1,0<H^{\prime}<3,322$ produktivitas cukup, kondisi \\ ekosistem cukup seimbang, \\ tekanan ekologis sedang

$\begin{array}{ll} & \text { Keragaman tinggi, stabilitas } \\ \mathrm{H}^{\prime}>3,322 & \text { ekosistem mantap, } \\ & \text { produktivitas tinggi, tahan } \\ & \text { terhadap tekanan ekologis. }\end{array}$

(Sumber: Hamidy, 2010)

Indeks keseragaman (Krebs, 1978) dengan menggunakan rumus :

Keterangan :

$$
J^{\prime}=\frac{H^{\prime}}{\log 2 s}=\frac{H^{\prime}}{H \text { maks }}
$$

$\mathrm{J}^{\prime}=$ indeks keseragaman (Evenness index)

$\mathrm{H}^{\prime}=$ indeks keragaman Shannon-Wiener

$\mathrm{S}=$ jumlah spesies $(3,3219 \log \mathrm{S})$

H'maks = Nilai maksimum

Indeks dominansi (Simpson, 1949 dalam Hamidy, 2010)

Keterangan :

$$
C=\sum_{i=1}^{s} p i^{2}
$$

$\mathrm{C}=$ Indeks dominansi Simpson

pi $=$ Proporsi spesies ke-i dalam komunitas

Asosiasi kepiting bakau berdasarkan habitat vegetasi mangrove dianalisis dengan cara melihat perbandingan nilai kelimpahan kepiting bakau dengan kelimpahan vegetasi mangrove tingkat pohon per stasiun pengamatan

\section{HASIL DAN PEMBAHASAN}

Pengambilan data yang dilakukan di Kelurahan Sumber jaya pada 3 stasiun penelitian dengan titik koordinat $03^{\circ} 53,832^{\prime}$ LU dan $102^{\circ} 18,727^{\prime}$ LS (stasiun 1) $03^{\circ}$ $53,915^{\prime}$ LU dan $102^{\circ} 18,742^{\prime}$ LS (stasiun 2) $03^{\circ} 53,967^{\prime}$ LU dan $102^{\circ} 18,757^{\prime}$ LS (stasiun 3). Di Kelurahan Sumberjaya, ekosistem mangrove seluas 92,5 hektar yang ditemui tersusun atas jenis Avicennia marina, Sonneratia alba, dan Rhizophora apiculata yang menempati daerah pinggiran sungai dan jauh dari garis pantai.

\section{Jenis dan Kelimpahan Vegetesai Mangrove}

Melimpahnya vegatasi mangrove pada suatu lokasi dapat dipengaruhi oleh beberapa faktor. Chapman (1977) dan Bunt dan Williams (1981) dalam Hafizh (2013), menyatakan bahwa hal tersebut berkaitan erat dengan tipe tanah (lumpur, pasir atau gambut), keterbukaan (terhadap hempasan gelombang), salinitas serta pengaruh pasang surut. 




Gambar 1. Grafik jenis dan kelimpahan vegetasi mangrove pada tiap stasiun.

Jenis Avicennia marina memiliki kelimpahan jenis tertinggi dengan nilai 500 ind/ha pada stasiun 3 (tiga), jenis Rhizophora apiculata 333,3 ind/ha pada stasiun 2 (dua), dan Sonneratia alba 266,67 ind/ha pada stasiun 1 (satu). Melimpahnya jenis Avicennia marina diduga karena jenis Avicennia marina merupakan jenis yang mampu hidup bertoleransi terhadap kisaran salinitas yang sangat besar. Macnae (1968) dalam Pramudji (2001) menyebutkan bahwa Avicennia marina mampu tumbuh pada salinitas sangat rendah sampai $90 \%$.

\section{Jenis Dan Kelimpahan Kepiting Bakau Pada Ekosistem Hutan Mangrove}

Secara keseluruhan ke-2 (dua) jenis kepiting bakau tersebar di semua stasiun pengamatan. Jenis Scylla paramamosain melimpah pada stasiun 1 (satu), sedangkan jenis Scylla olivacea melimpah pada staiun 2 (dua). Purwati dkk. (2009) menyatakan bahwa kedua spesies kepiting bakau yaitu jenis Scylla paramamosain dan Scylla olivacea pada lokasi penelitian saling berbagi habitat.

Berdasarkan hasil analisis kelimpahan kepiting bakau pada lokasi penelitian Kelurahan Sumber Jaya berkisar antara 104,34 ind/ha-180,67 ind/ha. Kelimpahan tertinggi dengan nilai kelimpahan 180,67 ind/ha terdapat pada stasiun 1 (satu) diikuti dengan nilai kelimpahan 147,67 ind/ha pada stasiun 3 (tiga) dan nilai kelimpahan 104,34 ind/ha pada stasiun 2 (dua) (Gambar 2).

Kepiting bakau jenis Scylla olivacea berbagi habitat dengan jenis Scylla paramamosain. Kepiting bakau jenis Scylla olivacea berukuran lebih kecil, dan memiliki struktur duri di permukaan tubuhnya yang tidak tajam dibandingkan dengan jenis Scylla paramomasain. Ini membuat Scylla olivacea bergerak leluasa di antara perakaran bakau yang rapat untuk proteksi terhadap predator. Sedangkan Scylla paramamosain lebih memanfaatkan duri-duri tajamnya untuk bertahan (Overton dan Macintosh, 2002 dalam Purwati dkk., 2010). 


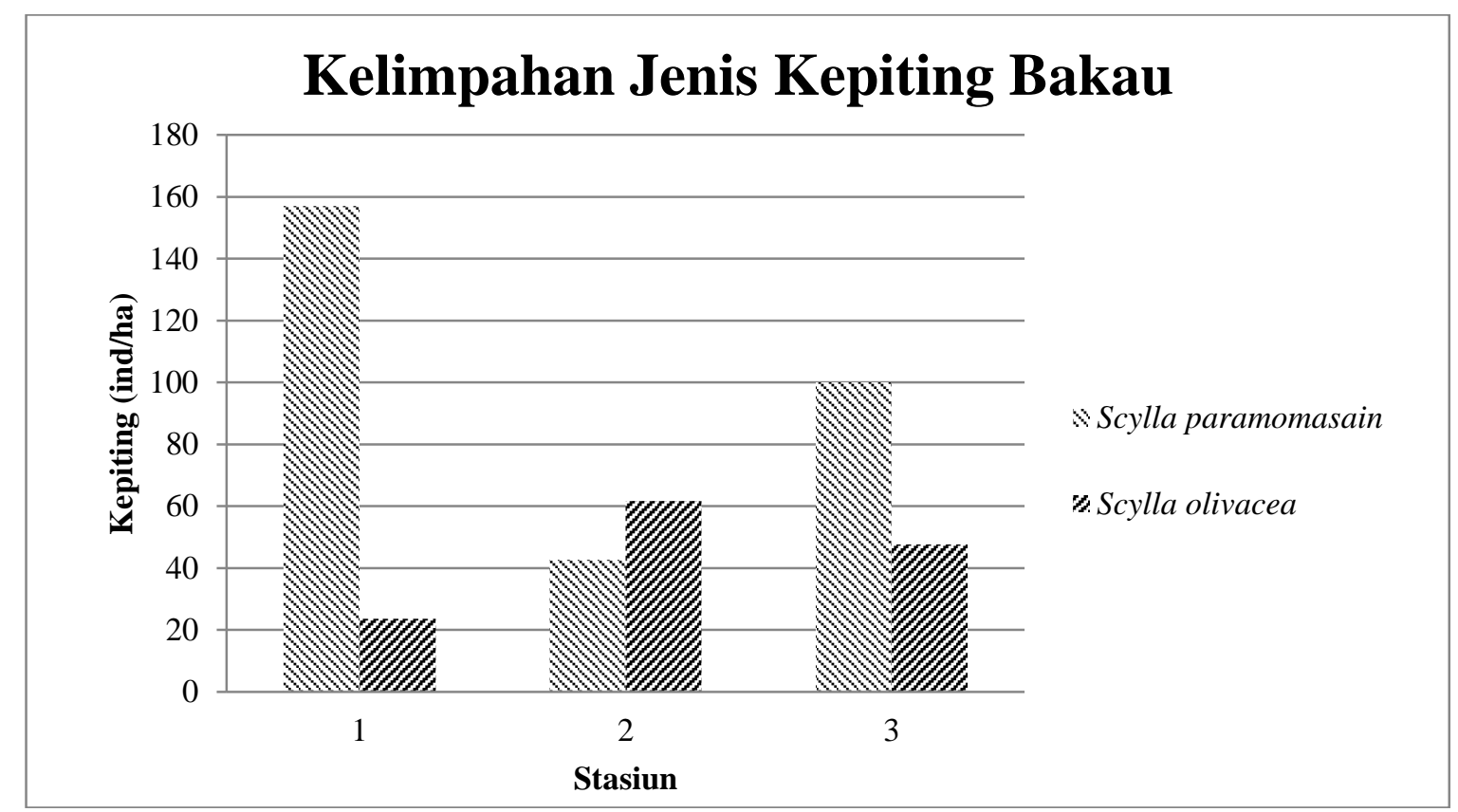

Gambar 2. Grafik jenis dan kelimpahan kepiting bakau pada tiap stasiun

\section{Indeks Keanekaragaman, Keseragaman Dan Dominansi Kepiting Bakau Pada Ekosistem Hutan Mangrove}

Odum (1998) dan Fachrul (2008) dalam Karmana (2010) mengatakan bahwa keanekaragaman identik dengan kestabilan suatu ekosistem, yaitu jika keanekaragaman suatu ekosistem tinggi, maka kondisi ekosistem tersebut cenderung stabil.

Menurut tolak ukur indeks keanekaragaman Shannon Wiener indeks keanekaragaman dari ketiga stasiun tergolong rendah karena hanya terdapat dua spesies yaitu jenis Scylla paramamosain dan Scylla olivacea. Hal tersebut menandakan bahwa keanekaragaman spesies pada ekosistem mangrove di kawasan ini telah mengalami tekanan ekologi yang mengakibatkan rendahnya nilai keanekaragaman. Menurut Krebs (1985) menyatakan bahwa indeks keseragaman antara $0-1$, jika nilai keseragaman mendekati 0 maka keseragaman rendah serta penyebaran jenis tidak merata mengakibatkan terlihatnya kecenderungan suatu jenis yang mendominasi. jenis yang paling jelas mendominasi yaitu jenis Scylla paramamosain yang melimpah pada stasiun pertama.

Tabel 2. Nilai Keanekaragaman (H'), Keseragaman (j'), dan Dominansi (C) pada Setiap Stasiun Pengamatan

\begin{tabular}{cccc}
\hline Stasiun & $\mathrm{H}^{\prime}$ & $\mathrm{j}^{\prime}$ & $\mathrm{C}$ \\
\hline 1 & 0.562 & 0.562 & 0.771 \\
\hline 2 & 0.976 & 0.976 & 0.516 \\
\hline 3 & 0.948 & 0.948 & 0.535 \\
\hline
\end{tabular}

Sumber : Hasil pengolahan data primer (2013)

\section{Asosiasi Kepiting Bakau Berdasarkan Habitat Hutan Mangrove}

Asosiasi kepiting bakau berdasarkan habitat hutan mangrovenya merupakan hasil membandingkan antara grafik kelimpahan mangrove dengan kelimpahan kepiting bakau tiap transek pengamatan. 




A.Stasiun 1

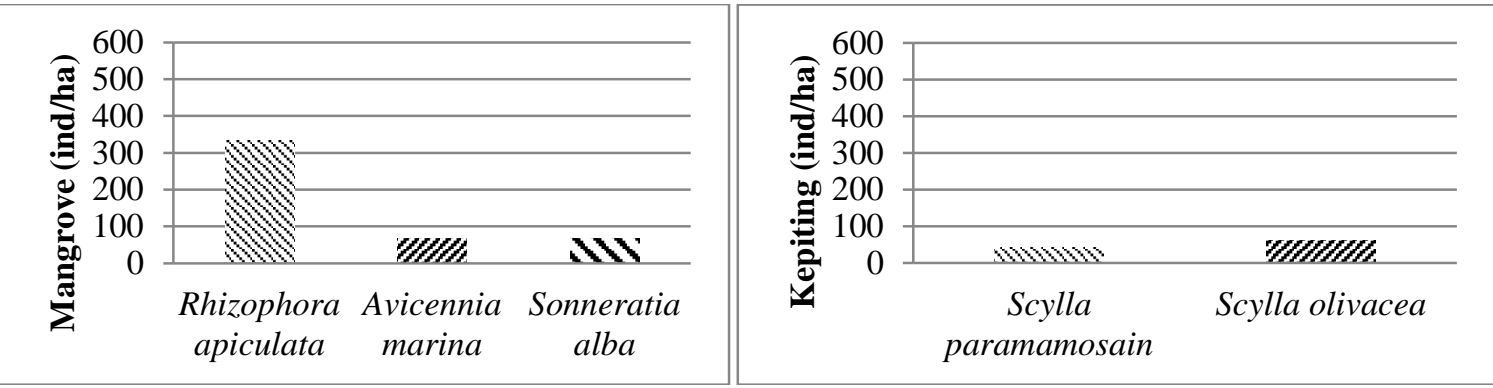

B.Stasiun 2
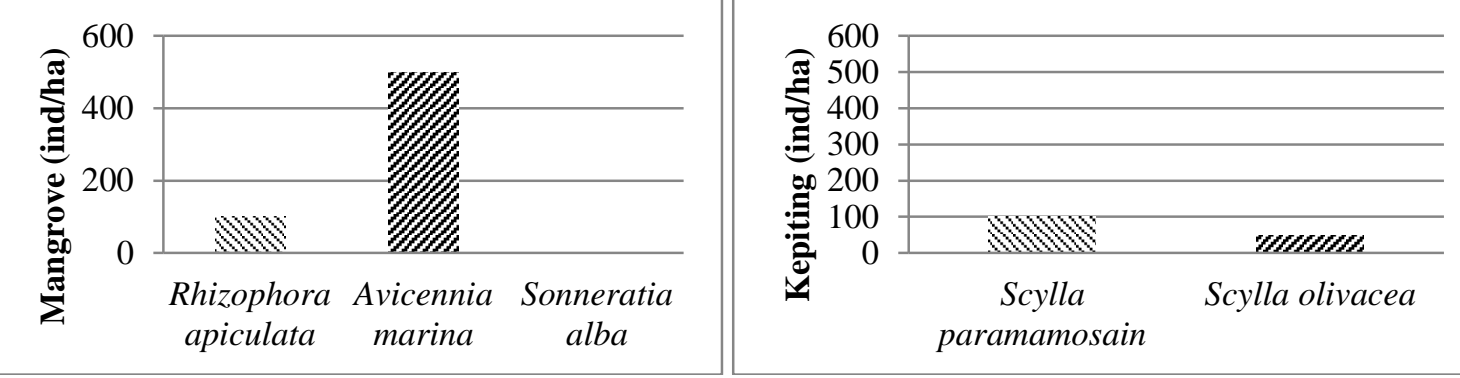

C.Stasiun 3

Gambar 3. Grafik rata-rata kelimpahan mangrove dan kelimpahan kepiting bakau per stasiun (A.stasiun 1, B. Stasiun 2, C.Stasiun 3)

Nilai korelasi vegetasi mangrove jenis Sonneratia alba dan Scylla paramamosain adalah 0,52 , nilai yang mendekati 1 menunjukan bahwa hubungan antara kelimpahan Sonneratia alba dengan kelimpahan kepiting bakau jenis Scylla paramamosain tinggi. Nilai korelasi Rhizophora apiculata dan Scylla olivacea adalah 0,23 . Nilai positif menunjukan bahwa terdapat hubungan yang baik antara Soneratia alba dan Scylla paramamosain serta Rhizophora apiculata dan Scylla olivacea .

Tingginya kelimpahan kepiting diperoleh pada stasiun 1 (satu), diduga karena habitat yang disenangi oleh kepiting bakau sesuai dengan habitat jenis mangrove dominan pada stasiun 1 (satu).

Pada stasiun 2 (dua) yang dominan ditumbuhi mangrove jenis Rhizophora apiculata, kepiting bakau jenis Scylla olivacea memiliki kelimpahan mencapai 61,67 ind/ha. Scylla olivacea memiliki tubuh yang lebih kecil dan struktur duri dipermukaan tubuhnya yang tidak tajam sehingga mempermudah ia bergerak leluasa di antara perakaran bakau yang rapat untuk proteksi terhadap predator (Purwati, 2010).

Melimpahnya kepiting bakau pada stasiun 3 (tiga) karena kondisi mangrove yang lebih baik dibandingkan stasiun lainnya. Kondisi, kerapatan, dan jenis mangrove akan berpengaruh terhadap luas penutupan kanopi dan bahan organik yang dihasilkan (Hogarth, 1999 dalam Ulum dkk., 2012).

Selain tumbuhan, banyak jenis hewan yang berasosiasi dengan hutan mangrove, baik yang hanya sekedar sebagian hidupnya memanfaatkan hutan mangrove, maupun seluruh hidupnya tergantung pada hutan mangrove. Lingkungan hutan mangrove 
menyediakan habitat yang baik berbagai fauna dengan adanya substrat dasar yang ternaung, pohon sebagai tempat menempel dan yang penting melimpahnya detritus organik sebagai sumber makanan (Hamidy, 2010)

\section{Parameter Fisika Kimia Perairan}

Tabel 3. Fisika Kimia air pada masing-masing stasiun pengamatan (2013)

\begin{tabular}{ccccc}
\hline No. Stasiun & $\begin{array}{c}\text { Suhu } \\
\left({ }^{\circ} \mathrm{C}\right)\end{array}$ & $\begin{array}{c}\text { Salinitas } \\
(\% \circ)\end{array}$ & $\begin{array}{c}\mathrm{pH} \\
(\% \circ)\end{array}$ \\
\hline 1 & 1 & 27,78 & 24,98 & 7,2 \\
\hline 2 & 2 & 27,17 & 24,78 & 7,14 \\
\hline 3 & 3 & 27,11 & 26,11 & 7,46 \\
\hline Rata-rata & 27,35 & 25,29 & 7,27 \\
\hline
\end{tabular}

Sumber : Data primer (2013)

Catatan : pengukuran dilakukan pada saat air surut

Jika dilihat dari hasil penelitian, perairan pada ekosistem mangrove ini merupakan perairan yang baik sebagai tempat hidup bagi kepiting bakau.

\section{Kesimpulan dan Saran}

Jenis kepiting bakau yang ditemukan di Kelurahan Sumber Jaya Kecamatan Kampung Melayu terdiri dari 2 (dua) yaitu jenis Scylla paramamosain dan jenis Scylla olivacea yang tersebar pada masing-masing stasiun pengamatan. Hutan mangrove di Kelurahan Sumber Jaya Kecamatan Kampung Melayu ditumbuhi oleh 3 spesies vegetasi mangrove yaitu terdiri dari mangrove jenis Sonneratia alba, Rhizophora apiculata, dan Avicennia marina

Indeks keanekaragaman $\left(H^{\prime}\right)$, keseragaman (E), dan dominasi (D) menunjukkan bahwa kepiting bakau pada ekosistem hutan mangrove Kelurahan Sumber Jaya Kecamatan Kampung Melayu dalam keadaan tidak stabil dimana jumlah individu setiap spesies tidak merata dan terdapt kecenderungan spesies yang mendominasi.

Kepiting bakau jenis Scylla paramamosain memiliki hubungan asosiasi yang baik pada kelompok vegetasi mangrove jenis Sonneratia alba. Sedangkan, kepiting bakau jenis Scylla olivacea lebih banyak ditemukan berasosiasi pada kelompok vegetasi mangrove jenis Rhizophora apiculata.

Parameter fisika kimia perairan seperti suhu, salinitas, dan derajat keasaman $(\mathrm{pH})$ dalam kondisi yang menujukan bahwa perairan hutan mangrove tersebut masih mendukung kehidupan biota-biota seperti kepiting bakau dan hutan mangrove itu sendiri.

Perlu diadakan penelitian lanjutan yang lebih seksama tentang kelimpahan kepiting bakau di ekosistem hutan mangrove Kelurahan Sumber Jaya Kecamatan Kampung Melayu, misalnya penelitian tentang kelimpahan kepiting bakau dengan kelimpahan hutan mangrove tingkat semai.

\section{DAFTAR PUSTAKA}

Brower, J.E. dan J.H Zar. 1989. Field and Laboratory Methods for General Ecology. W. M. Brown Company Publ. Dubuque Lowa.

Brower, J.Z. Yerrold, C. Von Ende, 1990. Field and Laboratory Methods for Genera Zoologi : Third Edition. W.M.C. Brown Publiser United States of America. P. HIm

Hamidy, R. 2010. Struktur Dan Keragaman Komunitas Kepiting Di Kawasan Hutan Mangrove Stasiun Kelautan Universitas Riau, Desa Purnama Dumai. Journal of Environmental seiense. Program Studi Ilmu Lingkungan PPS. Universitas Riau. 
Karmana, I. W. 2010. Analisis Keanekaragaman Epifauna Dengan Metode Koleksi Pitfall Trap Di Kawasan Hutan Cangar Malang. Ganec Swara Vol.4 No.1 Februari 2010.

Krebs, C. J. 1978. Ecology. The Experimental Analysis of Distribution and Abudance, Second Edition. Harper \& Row Publishers, New York.

Noor, Y. R., Khazali, M., dan Suryadiputra, I. N. N., 2006. Panduan Pengenalan Mangrove di Indonesia. Bogor: PHKA/WI-IP.160 - 162.

Pramudji, 2001. Ekosistem Hutan Mangrove Dan Peranannya Sebagai Habitat Berbagai Fauna Aquatik. Oseana, Volume XXVI, Nomor 4, 2001:13 - 23.

Purwati, P., R. Pratiwi., A. Prasetyo dab Y. I Ulumuddin. 2009. Kepiting Bakau: Scylla serrata, S. tranquebarica., S. paramamosain, S. olivacea. Puslit. OseanografiLIPI: 10 hal.

Purwati, P. N. Dhewani. Susetio. 2010. Kepiting Bakau Untuk Mata Pencaharian. Coremap II - LIPI. Jakarta. 2010.

Setyobudiandi, I. Sulistiono. F. Yulianda. C. Kusmana. S. Hariyadi. A. Damar. A. Sembiring. Bahtiar. 2009. Sampling Dan Analisis Data Perikanan dan Kelautan Terapan Pengambilan Contoh di Wilayah Pesisir dan Laut. MAIKARA-FPIK. Institut Pertanian Bogor. 313 hal.

Ulum, M. M. Widianingsih. R. Hartati. 2012. Komposisi dan Kelimpahan Makrozoobenthos Krustasea di Kawasan Vegetasi Mangrove Kel. Tugurejo, Kec. Tugu, Kota Semarang. Journal Of Marine Research. Volume 1, Nomor 2, Tahun 2012, Halaman 243-251.

Wijaya, I. N. 2011. Pengelolaan Zona Pemanfaatan Ekosistem Mangrove Melalui Optimasi Pemanfaatan Sumberdaya Kepiting Bakau ( Scylla serrata) di Taman Nasional Kutai Provinsi Kalimantan Timur. Sekolah Pascasarjana. Institut Pertanian Bogor. 